\title{
Antiangiogenic properties of selected ruthenium(III) complexes that are nitric oxide scavengers
}

\author{
L Morbidelli', S Donnini', S Filippi ${ }^{2}$, L Messori ${ }^{3}$, F Piccioli $^{3}$, P Orioli ${ }^{3}$, G Sava $^{4}$ and M Ziche ${ }^{*, I}$ \\ 'Department of Molecular Biology, University of Siena, Via Aldo Moro 2, 53100 Siena, Italy; ${ }^{2}$ Department of Pharmacology, University of Florence, \\ Viale Pieraccini 6, 50139 Florence, Italy; ${ }^{3}$ Department of Chemistry, University of Florence, Via della Lastruccia 3, 50019 Sesto Fiorentino, Florence, Italy; \\ ${ }^{4}$ Callerio Foundation, Institute of Biological Research, Via A. Fleming 22-31, 34 I 27 Trieste, Italy
}

The nitric oxide synthase (NOS) pathway has been clearly demonstrated to regulate angiogenesis. Increased levels of NO correlate with tumour growth and spreading in different experimental and human cancers. Drugs interfering with the NOS pathway may be useful in angiogenesis-dependent tumours. The aim of this study was to pharmacologically characterise certain ruthenium-based compounds, namely NAMI-A, KPI339, and RuEDTA, as potential NO scavengers to be used as antiangiogenic/antitumour agents. NAMI-A, KPI339 and RuEDTA were able to bind tightly and inactivate free $\mathrm{NO}$ in solution. Formation of ruthenium-NO adducts was documented by electronic absorption, FT-IR spectroscopy and ' $\mathrm{H}-\mathrm{NMR}$. Pretreatment of rabbit aorta rings with NAMI-A, KPI339 or RuEDTA reduced endothelium-dependent vasorelaxation elicited by acetylcholine. This effect was reversed by 8-BrcGMP. The key steps of angiogenesis, endothelial cell proliferation and migration stimulated by vascular endothelial growth factor (VEGF) or NO donor drugs, were blocked by NAMI-A, KPI339 and RuEDTA, these compounds being devoid of any cytotoxic activity. When tested in vivo, NAMI-A inhibited angiogenesis induced by VEGF. It is likely that the antitumour properties previously observed for ruthenium-based NO scavengers, such as NAMI-A, are related to their NO-related antiangiogenic properties. British Journal of Cancer (2003) 88, |484- |49|. doi:I0.I038/sj.bjc.6600906 www.bjcancer.com (c) 2003 Cancer Research UK

Keywords: nitric oxide; ruthenium(III); angiogenesis; endothelial cells; migration; proliferation

Nitric oxide (NO) is an important signalling molecule that acts in many tissues to regulate different physiological and pathological processes. We demonstrated that NO stimulates angiogenesis and mediates the effect of a number of angiogenic molecules (Ziche et al, 1994, 1997; Parenti et al, 2001). In human tumours, NO plays an important role in tumour growth and progression (Wink et al, 1998), as also evidenced by the increased expression of nitric oxide synthase (NOS) found in a variety of tumours (Thomsen et al, 1994; Cobbs et al, 1995; Gallo et al, 1998; Klotz et al, 1998; Feng et al, 2002). Nitric oxide has been shown to be important for maintaining the vasodilator tone of tumours by regulating tumour blood flow (Fukumura et al, 1997), and is an active mediator of tumour angiogenesis (Gallo et al, 1998; Jadeski and Lala, 1999; Jadeski et al, 2000), intimately linked with cancer cell growth and metastasis. Other mechanisms responsible for stimulation of tumour progression and spreading by tumour-derived NO are stimulation of tumour cell invasiveness (Orucevic et al, 1999; Jadeski et al, 2000) as well as increased expression of angiogenic factors (Morbidelli et al, 2001; Feng et al, 2002).

The availability of drugs able to specifically target NOS or inactivate free NO in tumours can be regarded as a new alternative therapeutic approach to inhibit tumour angiogenesis. Systemic NOS inhibition through L-arginine derivatives in experimental

*Correspondence: Dr M Ziche; E-mail: ziche@unisi.it

Received 31 December 2002; revised 4 February 2003; accepted 10 February 2003 tumour models was demonstrated to be antitumoral, by reducing tumour volume and increasing tumour necrosis (Thomsen et al, 1997; Jadeski and Lala, 1999; Swaroop et al, 2000). However, an issue associated with NOS inhibitors is their lack of selectivity for the three isoforms of NOS (Garvey et al, 1997; Cobb, 1999; Cheshire, 2001). In the case of NO scavengers, the selectivity is based on the rate of reaction with NO, which is dependent on the concentration of $\mathrm{NO}$ and the scavenger. Ruthenium compounds, designed as NO scavengers, work by rapidly and efficiently reacting with NO (Bottomley, 1978; Fricker et al, 1997; Mosi et al, 2002, patent IPN: WO95/05814). These compounds have been shown to exhibit pharmacological activity in vitro and in a number of in vivo models for a variety of diseases including cancer (Clarke, 2002 and references therein). Furthermore, an angiogenesis inhibitory activity has been reported for NAMI-A (imidazolium trans-imidazole dimethylsulphoxide tetrachloro ruthenate, ImH[trans-RuCl4(DMSO)Im) (Sanna et al, 2002; Vacca et al, 2002), a novel ruthenium(III)-based compound developed for selectively treating solid tumour metastases (Sava and Bergamo, 1999).

The aim of the present study was to characterise the pharmacological properties of representative ruthenium(III) complexes on isolated aortic ring preparations and to test their efficacy in inhibiting NO-dependent angiogenesis both in vitro and in vivo. Specifically, we wanted to ascertain whether the NO scavenging ability of these ruthenium(III) complexes and the related interference with the angiogenic process might be the basis of the biological properties of these innovative metallodrugs. 


\section{MATERIALS AND METHODS}

\section{Drugs}

NAMI-A was a gift of Professor E Alessio (Department of Chemical Sciences, University of Trieste), KP1339 (sodium bis indazole tetrachloro ruthenate, $\mathrm{Na}\left[\right.$ trans $\left.-\mathrm{RuCl}_{4} \mathrm{Ind}_{2}\right]$ ) was provided by Professor B Keppler (Department of Inorganic Chemistry, University of Vienna), and RuEDTA (K[Ru(HEDTA)Cl]) was prepared according to the published procedure (Diamantis and Dubrawsky, 1981). The identity and purity of the compounds was checked by various analytical techniques including elemental analysis, absorption and FT-IR spectroscopy. The chemical features of these ruthenium(III) complexes are shown in Figure 1. RuEDTA is a classical ruthenium(III) aminopolycarboxylate complex whose chemical properties have been extensively documented in previous studies (Matsubara and Creutz, 1979; Diamantis and Dubrawsky, 1981); NAMI-A and KP1339 are mixed ligand ruthenium(III) complexes (Alessio et al, 1993; Kratz et al, 1994). All are characterised by the presence of one or more labile ligands that can be replaced by NO. All these ruthenium(III) complexes are soluble in aqueous physiological buffers. RuEDTA is sufficiently stable under physiological conditions except it slowly dimerises (Bottomley, 1978). Both NAMI-A and KP1339, when dissolved in water or in physiological buffers, progressively hydrolyse and release the ruthenium(III) bound chlorides giving rise to a number of hydrated and/or hydroxy ruthenium species, as described (Mestroni et al, 1994; Kung et al, 2001).

Different NONOates were used as source of NO, mainly MAHMA NONOate (Z-1- $\{N$-methyl- $N$-[6- $(N$-methylammoniohexyl)amino]\}diazen-1-ium-1,2-diolate, Alexis Biochemicals, Lausen, Switzerland).

Acetylcholine hydrochloride, noradrenaline [(-)arterenol hydrochloride], sodium nitroprusside (NaNP) and the cGMP stable analogue, 8-Br-cGMP, were purchased from Sigma (St Louis, MO, USA). Vascular endothelial growth factor (VEGF) was purchased form Peprotech (Calbiochem, Milan, Italy).

\section{NO-binding studies}

Binding of NO to the individual ruthenium(III) complexes was analysed by different spectroscopic techniques including visible absorption, FT-IR and ${ }^{1} \mathrm{H}-\mathrm{NMR}$. Visible spectrophotometric studies were carried out on a Perkin-Elmer Lambda 20 BIO instrument equipped with a thermostated cuvette. The hydrolysis of ruthenium(III) complexes and the NO binding processes were monitored continuously over $24 \mathrm{~h}$, acquiring spectra at $10 \mathrm{~min}$ intervals. The experiments were carried out in phosphate buffer $\left(\mathrm{NaH}_{2} \mathrm{PO}_{4} 50 \mathrm{~mm}, \mathrm{NaCl} 100 \mathrm{~mm}, \mathrm{pH} 7.4\right)$ at $25^{\circ} \mathrm{C}$, working at $100 \mu \mathrm{m}$ ruthenium(III) concentrations. FT-IR spectra of similar samples
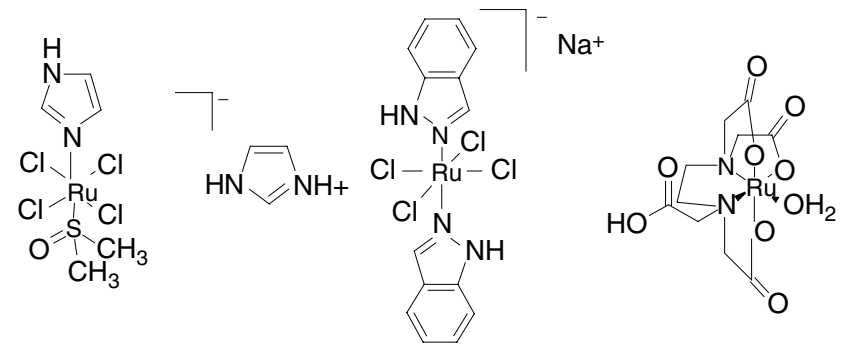

NAMI-A

KP1339

RuEDTA

Figure I Schematic representation of the chemical structure of NAMIA, KPI339 and RuEDTA as derived from crystallographic data. Notably, all complexes are characterised by the presence of at least one labile ligand. were recorded on a Perkin-Elmer Spectrum BXI instrument. $300 \mathrm{MHz}{ }^{1} \mathrm{H}$-NMR spectra were measured on a Gemini 2000 Varian Instrument. For ${ }^{1} \mathrm{H}-\mathrm{NMR}$ measurements, $1 \mathrm{~mm}$ samples were employed.

\section{Aortic ring relaxation}

The thoracic segment of the aorta was obtained from male New Zealand rabbits and cut into rings of $3-4 \mathrm{~mm}$ width (four to six rings from each aorta). The preparations were suspended between stainless-steel hooks and mounted in a $10 \mathrm{ml}$ organ bath filled with warmed $\left(37^{\circ} \mathrm{C}\right)$ and oxygenated $\left(95 \% \mathrm{O}_{2}, 5 \% \mathrm{CO}_{2}\right)$ Krebs solution. The incubation solution had the following composition (mM): $\mathrm{NaCl}$ 118, $\mathrm{NaHCO}_{3}, 25, \mathrm{KCl} 4.7, \mathrm{KH}_{2} \mathrm{PO}_{4} 1.2, \mathrm{MgSO}_{4}$ 1.2, $\mathrm{CaCl}_{2}$ 2.5, glucose 10. A tension of $2 \mathrm{~g}$ was applied and isometric contraction was recorded by a transducer on a polygraph chart (Battaglia Rangoni). After 60-90 min of equilibration, a concentrationresponse curve for noradrenaline (NA, $0.1-1 \mu \mathrm{M}$ ) was performed and a concentration able to induce $50 \%$ of the maximum effect was chosen. Following wash-out, the rings were preconstricted with this concentration of NA and the cumulative relaxant effect of acetylcholine (ACh, $0.1-10 \mu \mathrm{M}$ ) was tested. The value of tension developed following NA administration $(1168 \pm 68 \mathrm{mg}, n=7)$ was taken as $100 \%$ and the effect of ACh was referred to this value. The vasorelaxant effect of ACh was tested $10 \mathrm{~min}$ after the contractile response to NA was fully developed. Experiments in which $10 \mu \mathrm{m}$ ACh induced a maximum relaxant effect of less than $40 \%$ were discarded. The preparation was then washed, and a second concentration-relaxant effect curve for ACh was obtained in the same preparation preconstricted by $\mathrm{NA}$ in the presence of test compounds with or without 8 -Br-cGMP (30 min exposure).

\section{Cell lines and culture conditions}

Coronary venular endothelial cells (CVEC) were isolated and characterised as previously described (Morbidelli et al, 1996). Cells were maintained in culture in Dulbecco's modified Eagle's medium (DMEM) supplemented with $10 \%$ bovine calf serum (CS) and antibiotics (100 $\mathrm{U} \mathrm{ml}^{-1}$ penicillin and $100 \mu \mathrm{g} \mathrm{ml}^{-1}$ streptomycin) on gelatin-coated dishes. Cells were cloned and each clone was subcultured up to a maximum of 25 passages. Passages between 15 and 20 were used in these experiments.

\section{Cytotoxicity}

The cytotoxic effect of test substances was studied by trypan blue exclusion. Briefly, endothelial cells were suspended in $0.1 \%$ CS medium supplemented with increasing concentrations of the test compounds and incubated at $37^{\circ} \mathrm{C}$ for $4 \mathrm{~h}$. Cells were then counted in a haemocytometer and the percentage of dead cells over the total number of cells was calculated.

\section{Migration assay}

Cell migration was assessed in 48-well microchemotaxis chambers (NeuroProbe, Biomap, Milan, Italy) on a polycarbonate filter ( $8 \mu \mathrm{m}$ pore size). The filter was coated with type I collagen $\left(100 \mu \mathrm{g} \mathrm{ml}^{-1}\right)$ and bovine plasma fibronectin $\left(10 \mu \mathrm{g} \mathrm{ml}^{-1}\right)$. A cell suspension containing 12500 cells was added to the upper chamber of each well. Test compounds were added to the cells in the upper compartments, while angiogenic factors or NO donor drugs were placed in the lower wells. After for $4 \mathrm{~h}$ at $37^{\circ} \mathrm{C}$, cells that had not migrated were removed and the filter was stained with Diff-Quik (Biomap, Milan, Italy). Migrated cells were counted in 10 random fields per well at a magnification of 400 (Ziche et al, 1997). 


\section{Cell proliferation/survival}

Cell proliferation and survival were quantified by total cell number as reported (Ziche et al, 1997). Briefly, $1.5 \times 10^{3}$ cells resuspended in $10 \%$ CS were seeded in each well of 96 multiwell plates. After adherence $(4 \mathrm{~h})$ the medium was replaced with $1 \%$ CS medium containing test compounds in the absence or in the presence of the angiogenic factors VEGF or the NO donor drug NaNP, and incubated for $48 \mathrm{~h}$. The supernatants were removed from the multiwell plates and the cells were fixed with methanol and stained with Diff-Quik. Cell numbers were obtained by counting seven random fields at a magnification of 100 with the aid of an ocular grid.

\section{Rabbit corneal angiogenesis assay}

Corneal assays were performed in New Zealand white rabbits (Charles River, Calco, Como, Italy) in accordance with the guidelines of the European Economic Community for animal care and welfare (EEC Law No. 86/609). Briefly, after being anaesthetised with sodium pentothal $\left(30 \mathrm{mg} \mathrm{kg}^{-1}\right)$, slow-release pellets bearing test substances were implanted in micropockets surgically produced in the lower half of the cornea. Subsequent daily observation of the implants was made with a slit-lamp stereomicroscope without anaesthesia. An angiogenic response was scored positive when budding of vessels from the limbal plexus occurred after 3-4 days and capillaries progressed to reach the implanted pellet. The angiogenesis score was calculated (vessel density $\times$ distance from the limbus) as described (Ziche et al, 1997).

\section{Statistical analysis}

Results are expressed as mean values \pm s.e.m. Multiple comparisons were performed by one-way ANOVA and individual differences tested by Fisher's test after the demonstration of significant intergroup differences by ANOVA.

\section{RESULTS}

\section{Reaction of ruthenium(III) compounds with NO}

Reactions of NAMI-A, KP1339 and RuEDTA with NO were carried out in the reference phosphate buffer and analysed by absorption and FT-IR spectroscopies and by ${ }^{1} \mathrm{H}-\mathrm{NMR}$. MAHMA NONOate was used as the source of NO. Notably, each MAHMA molecule releases two $\mathrm{NO}$ equivalents. The molar ratio MAHMA/Ru(III) used in this study was $2: 1$.

In the case of RuEDTA, NO bound quickly to the ruthenium(III) centre blocking RuEDTA dimerisation, in agreement with previous results by Fricker (Davies et al, 1997; Fricker, 1999; Fricker et al, 1997). The main product of the reaction was the diamagnetic RuEDTA - NO adduct, characterised by an intense FT-IR band at $1880 \mathrm{~cm}^{-1}$.

FT-IR spectra for NO adducts of either NAMI-A or KP 1339 are shown in Figure 2. Intense transitions, at 1850 and $1840 \mathrm{~cm}^{-1}$ respectively, were observed indicating formation of the [ $\mathrm{Ru}-\mathrm{NO}]$ moiety. Independent NMR data showed that both paramagnetic ruthenium(III) complexes upon reaction with NO rapidly transformed into related diamagnetic species, formally containing the $\left\{\mathrm{Ru}^{\mathrm{II}} \mathrm{NO}^{+}\right\}$moiety (data not shown). For all complexes, the disappearance of the paramagnetic lines and the associated formation of the $\mathrm{NO}$ adducts was complete within a few minutes.

\section{Influence of NO scavengers on ACh-induced relaxation in aortic rings}

The pharmacological characterisation of the above compounds was performed in rabbit aortic ring preparations bearing intact endothelium.
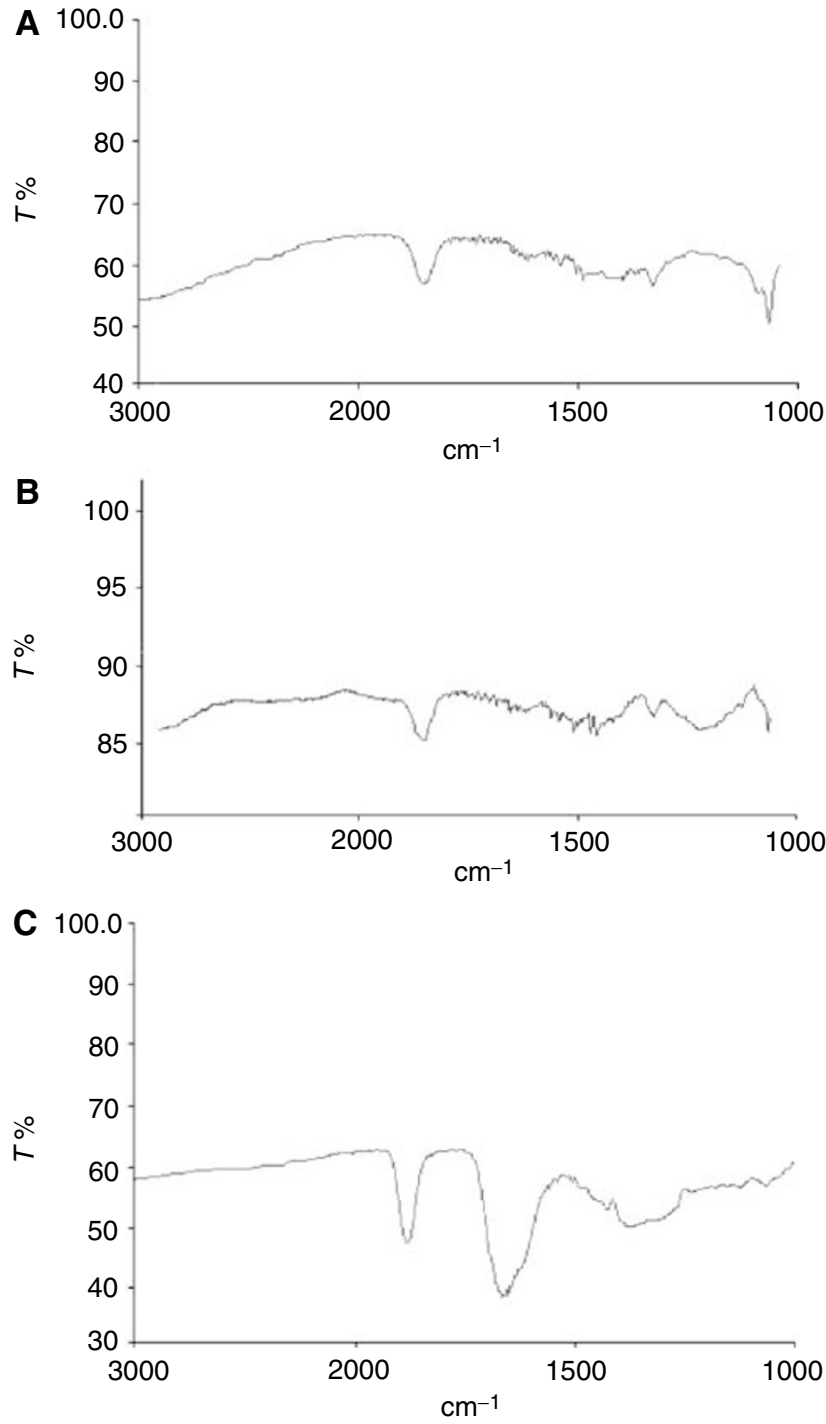

Figure 2 FT-IR spectra of the reaction products of NAMI-A $(\mathbf{A})$ KPI339 (B) and RuEDTA (C) with NO. The intense band observed in the $1900-1800 \mathrm{~cm}^{-1}$ range is diagnostic of the presence of an Ru-NO moiety.

Vessel preparations were incubated for $30 \mathrm{~min}$ at $37^{\circ} \mathrm{C}$ with increasing concentrations of the compounds $(0.1-3 \mu \mathrm{m}$ for NAMIA, $1-100 \mu \mathrm{M}$ for $\mathrm{KP} 1339$ and $1-100 \mu \mathrm{M}$ for RuEDTA) before challenging with ACh. NAMI-A, KP1339 and RuEDTA were able to interfere to a variable extent with $\mathrm{ACh}$-induced vasorelaxation in a concentration-dependent manner (Figure 3). The rank order of potency was the following: NAMI-A $>$ RuEDTA $>$ KP1339 with $\mathrm{EC}_{50} \mathrm{~s}$ for $1 \mu \mathrm{M}$ ACh-induced relaxation of approximately $0.3,1$ and $10 \mu \mathrm{M}$, respectively. The maximum effect caused by $10 \mu \mathrm{m}$ ACh was reduced by about $90 \%$ in the presence of $3 \mu \mathrm{M}$ NAMI-A and by $80 \%$ in the presence of $100 \mu \mathrm{M}$ RuEDTA. Not only the extent of vasorelaxation was reduced by $\mathrm{NO}$ scavengers but also the time required to obtain it. In the presence of NAMI-A, KP1339 and RuEDTA, ACh-induced vasorelaxation was obtained within 60-90, $90-120$ and $90-120 \mathrm{~s}$, respectively, $v s 35-40 \mathrm{~s}$ in the absence of drugs.

We then tested whether the molecular mechanism of these NO scavengers was because of inhibition of NO biosynthesis. Since cyclic GMP (cGMP) and protein kinase G (PKG) are the intracellular effectors of the vasodilatory effect of NO, we checked whether the addition of 8 -Br-cGMP, a stable cell-permeable 
A ACh $(\mu \mathrm{M})$
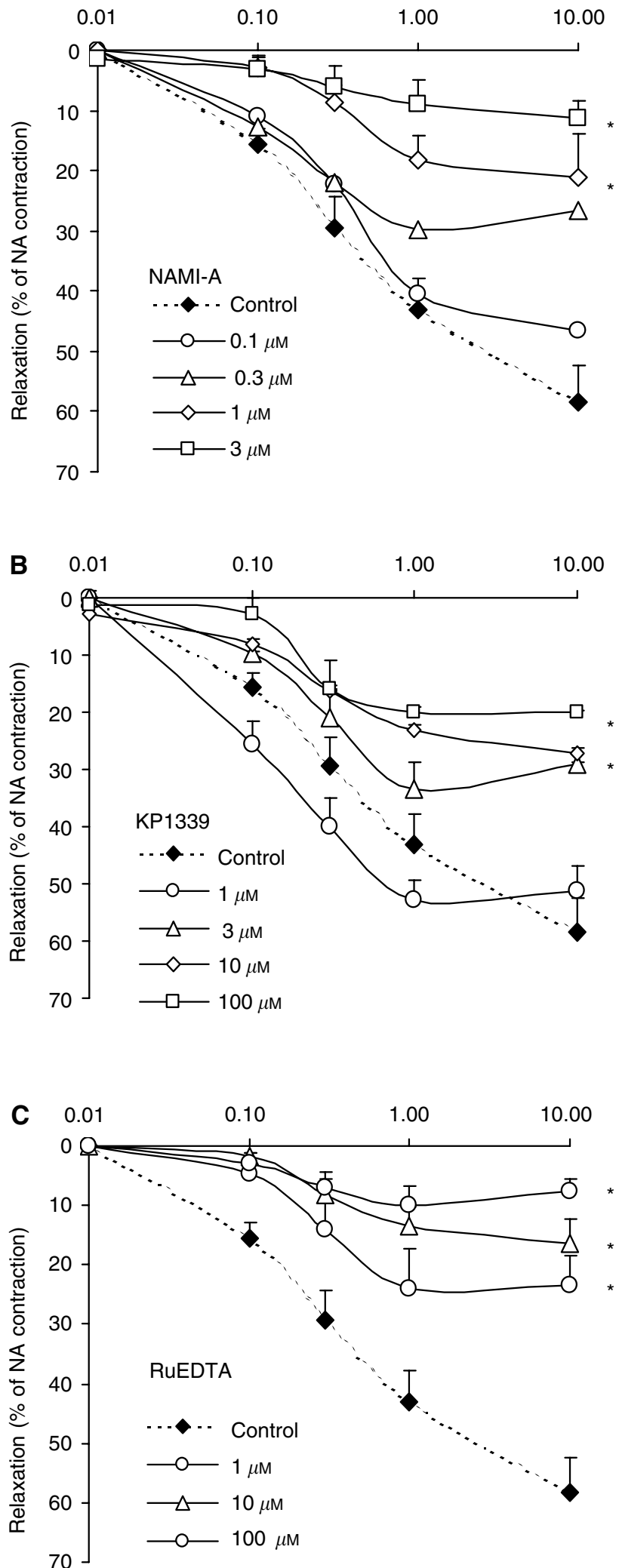

Figure 3 Vasodilator responses of aortic ring preparations by increasing concentrations of ACh. Noradrenaline (NA)-preconstricted rabbit aortic rings were exposed to Krebs solution in the absence and in the presence of increasing concentrations $(0.1-3 \mu \mathrm{M})$ of NAMI-A $(\mathbf{A}),(I-100 \mu \mathrm{M})$ of $\mathrm{KPI} 339(\mathbf{B})$, and $(\mathrm{I}-100 \mu \mathrm{M})$ of RuEDTA $(\mathbf{C})$ before stimulation with ACh $(0.1-10 \mu \mathrm{M})$. Vasodilatation is compared to ACh-induced responses. Data are means \pm s.e.m. of five ring preparations. ${ }^{*} P<0.05$ vs basal. analogue of cGMP, could revert the vasoconstrictive effect of these NO scavengers. In the presence of $1 \mu \mathrm{M}$ NAMI-A, $3 \mu \mathrm{M} 8$-Br-cGMP was able to restore the vasodilatory effect of ACh by $66 \%$ (data not shown).

\section{Effect of NO scavengers on endothelial cell migration}

Microvascular endothelial cell migration and proliferation are key events of the angiogenesis process. As previously demonstrated,
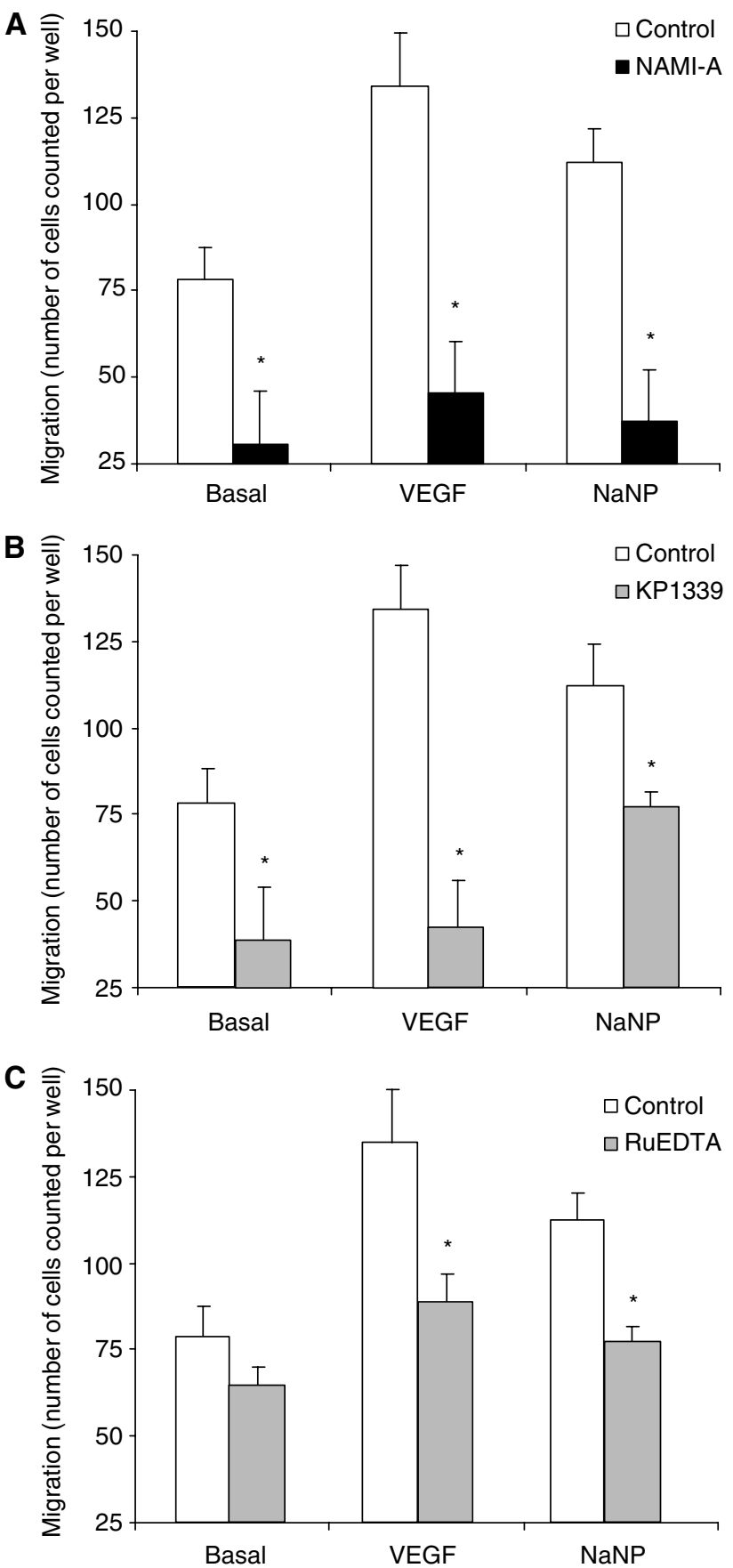

Figure 4 Migration of postcapillary endothelial cells towards VEGF or exogenous NO. Following incubation with $\mathrm{NO}$ scavengers ( $3 \mu \mathrm{M}$ NAMI-A, $3 \mu \mathrm{M} \mathrm{KPI} 339$ or $30 \mu \mathrm{M}$ RuEDTA) endothelial cells were challenged towards gradients of VEGF or NaNP in microchemotaxis Boyden chambers. After $4 \mathrm{~h}$, cell migration was measured by microscopic examination. Data (means \pm s.e.m.) are reported as the number of cells counted per well ( $n=3$ in triplicate). ${ }^{*}<0.05$ vs control. 
VEGF and NaNP are able to induce endothelial cell migration. The effect of VEGF is mediated by the activation of endothelialconstitutive NOS, NO production and cGMP accumulation (Morbidelli et al, 1996; Ziche et al, 1997). Endothelial cells exposed to NO scavengers were thus challenged toward a gradient of VEGF $\left(20 \mathrm{ng} \mathrm{ml}^{-1}\right)$ or NaNP $(10 \mu \mathrm{M})$. Cells pretreated with NAMI-A or KP1339 ( $3 \mu \mathrm{M}$ each) or RuEDTA $(30 \mu \mathrm{M})$ showed reduced numbers of migrating cells in the basal condition, and these compounds were able to block completely the migratory effect elicited by VEGF or NaNP (Figure 4). KP1339 was the least effective in reducing NaNP-induced migration, in accordance with the pharmacological data on ACh-induced vasorelaxation.

The inhibitory effect of metallodrugs was not because of cytotoxicity, since no statistically relevant toxic effect was observed in endothelial cell suspensions exposed to the NO scavengers for $4 \mathrm{~h}$ at $37^{\circ} \mathrm{C}$ (Table 1$)$.

\section{Effect of NO scavengers on endothelial cell proliferation}

Endothelial cell proliferation is potently stimulated by either VEGF or exogenous NO, the former acting through NOS and MAPK pathway (Morbidelli et al, 1996; Parenti et al, 1998). As shown in Figure $5(\mathrm{~A}-\mathrm{C})$, endothelial cell proliferation induced by VEGF $\left(20 \mathrm{ng} \mathrm{ml}^{-1}\right)$ or NaNP $(10 \mu \mathrm{M})$ was markedly inhibited by all NO scavengers ( $3 \mu \mathrm{M}$ NAMI-A or KP1339 or $30 \mu \mathrm{m}$ RuEDTA). The blockade of cell growth was accompanied by a change in their morphology with the appearance of cytoplasmic vacuoles (data not shown).
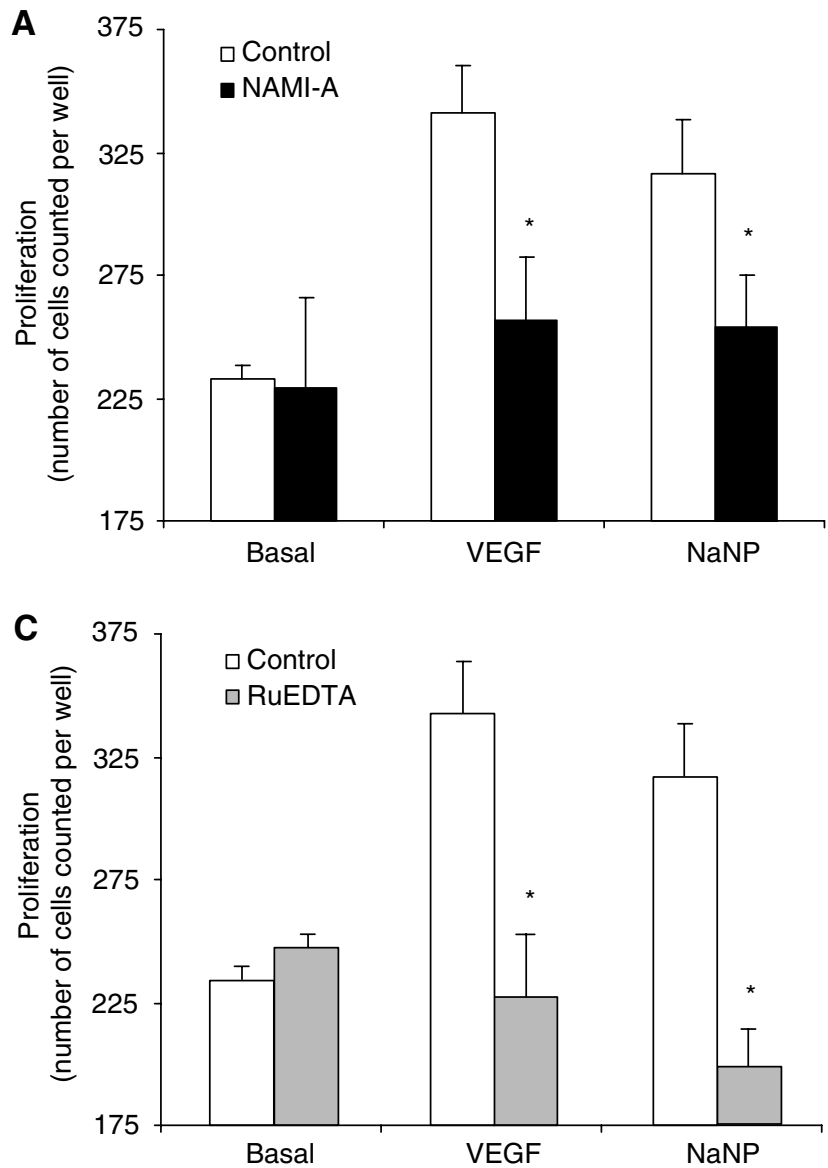

Table I Lack of cytotoxic effect of NO scavengers on endothelial cells

\begin{tabular}{cccc}
\hline Concentration $(\boldsymbol{\mu} \mathbf{M})$ & NAMI-A & KPI339 & Ru-EDTA \\
\hline 0 & $6 \pm 3$ & $6 \pm 3$ & $6 \pm 3$ \\
1 & $15 \pm 5$ & $6 \pm 1$ & ND \\
3 & $13 \pm 4$ & $8 \pm 1$ & ND \\
10 & $15 \pm 5$ & $8 \pm 5$ & $9 \pm 5$ \\
100 & $9 \pm 1$ & $11 \pm 1$ & $12 \pm 3$ \\
\hline
\end{tabular}

Cytotoxicity of compounds was studied in endothelial cells by trypan blue exclusion after $4 \mathrm{~h}$ of incubation at $37^{\circ} \mathrm{C}$. Data (means \pm s.e.m.) are reported as the percentage of dead cells over the total number of cells counted. ND = not determined.

When cells were incubated with $3 \mu \mathrm{M}$ NAMI-A in the presence of $100 \mu \mathrm{M} 8$-Br-cGMP, the proliferative effect of NaNP and VEGF was restored (Figure 5D), demonstrating that the molecular mechanism of NAMI-A in interfering with endothelial cell growth was the blockade of soluble NO.

\section{Effect of NO scavengers on in vivo angiogenesis}

The antiangiogenic activity of NAMI-A observed in isolated cells was also expressed in vivo in the avascular rabbit cornea against the strong angiogenic response elicited by VEGF. Slow-release pellets were prepared incorporating two different doses of NAMIA, namely 200 and $500 \mathrm{ng}$, alone and in the presence of $200 \mathrm{ng}$ VEGF. NAMI-A did not affect angiogenesis 'per se' and did not
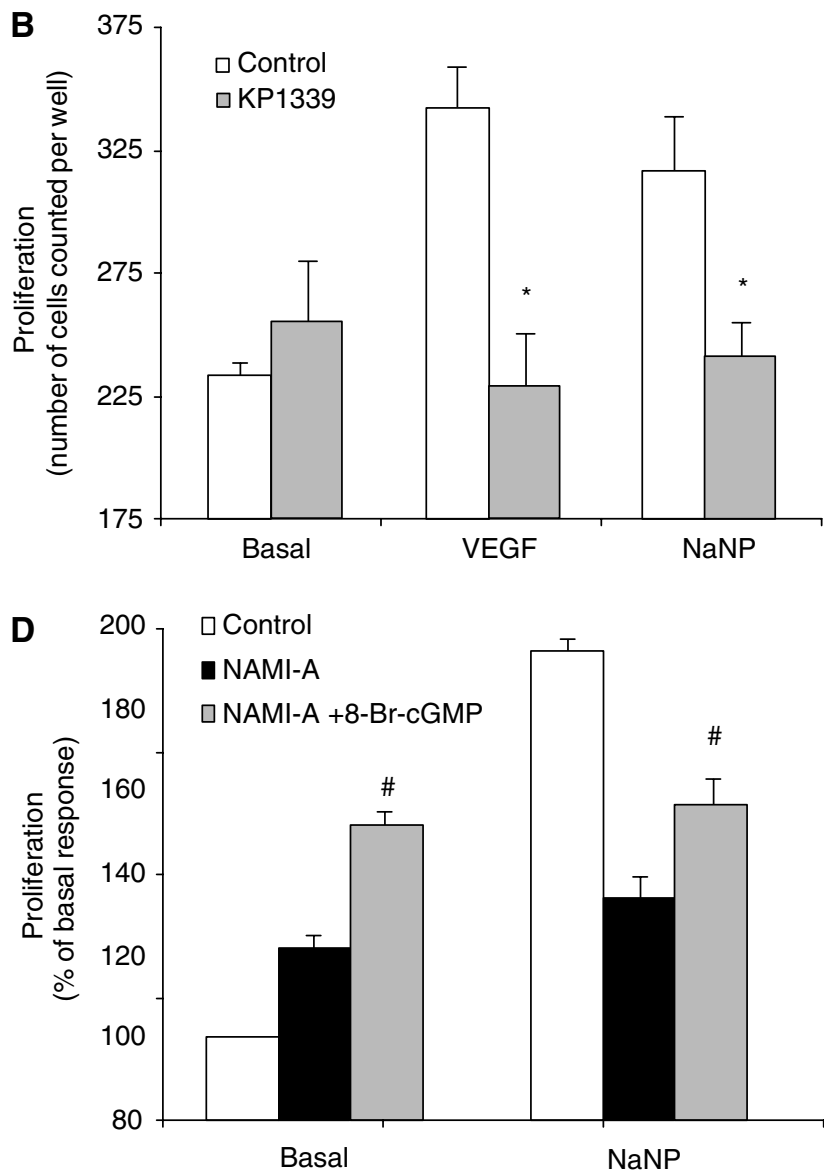

Figure 5 Proliferation of postcapillary endothelial cells in the presence of VEGF or exogenous NO. (A-C) Cells were incubated in the absence and in the presence of $\mathrm{NO}$ scavengers ( $3 \mu \mathrm{M}$ NAMI-A, $3 \mu \mathrm{M}$ KPI339 or $30 \mu \mathrm{M}$ RuEDTA). Cell proliferation was monitored after $48 \mathrm{~h}$ incubation. Data (means \pm s.e.m.) are reported as number of cells counted per well. (D) Cell proliferation in response to $10 \mu \mathrm{M}$ NaNP was studied in endothelial cells exposed to $3 \mu \mathrm{M}$ NAMI-A in the presence of $100 \mu \mathrm{M} 8$-Br-cGMP ( $n=3$ in triplicate). ${ }^{*} P<0.05$ vs control and ${ }^{\#} P<0.05$ vs NAMI-A alone. 
induce any inflammatory response. The compound was able to inhibit VEGF-induced response completely (Figure 6).

\section{DISCUSSION}

Ruthenium(III) complexes are an emerging family of metallodrugs that are finding application as potential agents for the treatment of cancer, septic shock, immune diseases and other pathological conditions (Clarke et al, 1999). Among these agents, NAMI-A, a compound found to be active against lung metastases (Sava and Bergamo, 1999), tumour cell invasion (Zorzet et al, 2000), and recently to possess antiangiogenesis properties (Pintus et al, 2002; Sanna et al, 2002; Vacca et al, 2002) is presently undergoing clinical trials as an antimetastatic agent.

Three representative ruthenium(III) complexes, namely NAMIA, KP1339 and RuEDTA were selected for further investigation in an attempt to relate the NO scavenging properties to their activity on the angiogenesis process. Unambiguous evidence for the formation of tight ruthenium-nitrosyl adducts, and therefore NO scavenging properties are here reported for NAMI-A and KP1339. The properties of RuEDTA, previously reported (Davies et al, 1997), have been confirmed.

Notably, these three complexes, upon reaction with NO, even at stoichiometric ratios, exhibit a spectral behaviour that is diagnostic of the formation of stable ruthenium-nitrosyl species, that is the appearance of an intense IR transition at 1900$1800 \mathrm{~cm}^{-1}$ and the disappearance of the hyperfine signals in the ${ }^{1} \mathrm{H}$-NMR spectra owing to loss of paramagnetism. In all cases the reaction is complete within a few minutes.
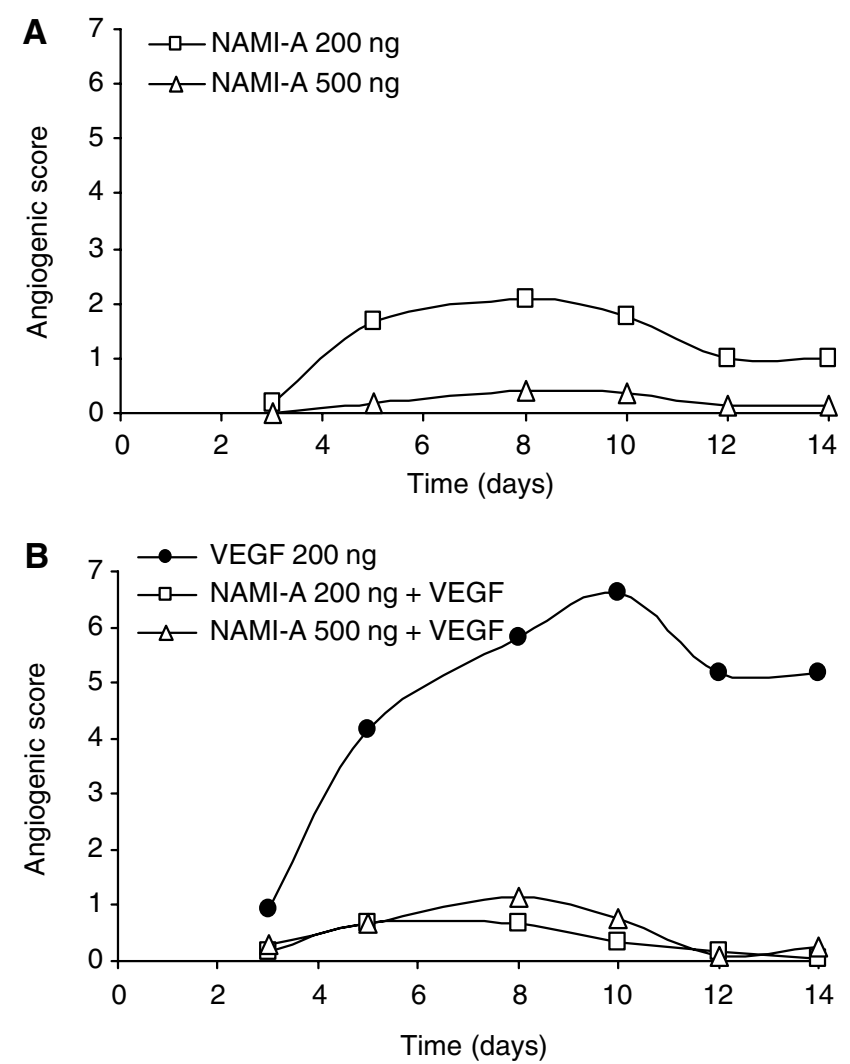

Figure 6 Effect of NAMI-A on in vivo angiogenesis in the rabbit corneal model. Pellets bearing NAMI-A and/or VEGFI65 were prepared and surgically implanted in the corneal stroma of albino rabbits. The angiogenic response of NAMI-A was tested per se $(\mathbf{A})$ and in the presence of VEGF (B). Data are reported as angiogenic score during time (days). Numbers are means of at least three implants per experimental point.
The relaxation induced in rabbit isolated vessels by $\mathrm{ACh}$, an experimental paradigm originally employed for revealing the role of NO in mediating blood vessel relaxation (Furchgott and Zawadzki, 1980), is inhibited by all ruthenium complexes examined, demonstrating their ability to interfere with NO binding also in biological systems. NAMI-A is the most potent, whereas KP1339 the weakest agent in antagonising the NO-mediated effects. Reversal of the inhibition by $8-B r-c G M P$, the intracellular NO effector, clearly indicates that these complexes prevent NO from exerting its action without affecting the intracellular relaxation mechanism.

Endothelial cell functions linked to angiogenesis such as migration and proliferation, typically stimulated by exogenous NO donors (NaNP) or VEGF, the latter leading to sequential activation of NOS and of the GMP-dependent kinase cascade (Morbidelli et al, 1996; Ziche et al, 1997; Parenti et al, 1998), are exquisitely sensitive to ruthenium complexes. All compounds reduce, to a different extent, the migration of endothelial cells. Similarly, the ruthenium complexes affect the stimulated proliferation of endothelial cells measured at $48 \mathrm{~h}$, indicating their long-lasting effects as NO scavengers. Since 8-Br-cGMP counteracts the inhibition exerted by ruthenium compounds on the proliferative effects elicited by NaNP or VEGF, it appears that the action of these compounds is again exclusively confined to the capture of nascent NO, without affecting the intracellular mechanisms involved in proliferation. The absence of cell toxicity further support the notion that these compounds, at the concentrations examined, have no major intracellular effects. The efficacy of NAMI-A as a NO scavenger, observed in in vitro conditions driven by an increased availability of $\mathrm{NO}$, is confirmed in vivo in the rabbit cornea assay. The compound exerts strong inhibition towards VEGF, whose angiogenic response has been shown to be dependent on the activation of the NOS pathway (Ziche et al, 1997; Ziche and Morbidelli, 2000).

The results of this study confirm recent findings on NAMI-A demonstrating its inhibitory activity on proliferation, cell migration and production of degradative enzymes (Vacca et al, 2002; Sanna et al, 2002). Also the antiangiogenic properties previously observed in the chorioallantoic membrane (Vacca et al, 2002) are confirmed in our in vivo assay in the rabbit cornea.

The inhibition of angiogenesis exerted by NAMI-A has been attributed to induction of apoptosis, which in turn is linked to inhibition of the mitogen-activated protein kinase (MAPK) signalling pathway and heat shock protein-27 downregulation (Pintus et al, 2002; Sanna et al, 2002). Since MAPK is a downstream effector of the NOS/cGMP pathway (Parenti et al, 1998), its inhibition by NAMI-A may be caused by the NO-binding activity here reported. In support of this interpretation, involving $\mathrm{NO}$ as a crucial signalling molecule, is the finding that a cGMP stable analogue is able to revert the antiangiogenic effect of NAMI-A.

In conclusion, this study demonstrates that ruthenium(III) compounds inhibit NO-dependent angiogenesis, and highlights a rather innovative mechanism of action for heavy metal-based compounds, which are currently hypothesised to act via DNAbinding (Malina et al, 2001). The antimetastatic activity of these metallodrugs might be multiple, interfering with the endothelial cell functions during angiogenesis, angiogenic factor overexpression, the vasodilating state of tumours and probably tumour cell invasiveness, each event being demonstrated by different groups as NO-dependent (Fukumura et al, 1997; Gallo et al, 1998; Jadeski and Lala, 1999; Orucevic et al, 1999; Jadeski et al, 2000; Morbidelli et al, 2001; Feng et al, 2002). On the speculative side, it may be suggested that tumours producing high NO levels and exhibiting a high angiogenic output would be more sensitive to ruthenium(III)based drugs. 


\section{ACKNOWLEDGEMENTS}

We are grateful to Professors A Giachetti (Lifetech srl, Florence) and R Schulz (University of Alberta) for the helpful discussion. We thank Professors Bernhard Keppler and Enzo Alessio for providing the ruthenium complexes. This work was supported by funds from the Italian Ministry for the University (MIUR), the National Research Council of Italy (CNR, Target Project 'Biotechnologies') and the Italian Association for Cancer Research (AIRC).

\section{REFERENCES}

Alessio E, Calducci G, Lutman A, Mestroni G, Calligaris M, Attia WM (1993) Synthesis and characterization of two new classes of ruthenium(III)-sulfoxide complexes with nitrogen donor ligands (L): $\mathrm{Na}\left[\right.$ trans $\left.-\mathrm{RuCl}_{4}\left(\mathrm{R}_{2} \mathrm{SO}\right)(\mathrm{L})\right]$. The crystal structure of $\mathrm{Na}\left[\right.$ trans $-\mathrm{RuCl}_{4}(\mathrm{DM}-$ $\left.\mathrm{SO}\left(\mathrm{NH}_{3}\right)\right]$ 2DMSO, $\mathrm{Na}\left[\right.$ trans- $\mathrm{RuCl}_{4}$ (DMSO) (Im)] $\mathrm{H}_{2} \mathrm{O}, \mathrm{Me}_{2} \mathrm{CO}$ (Im$=$ imidazole) and mer, cis- $\mathrm{RuCl}_{3}(\mathrm{DMSO})(\mathrm{DMSO})\left(\mathrm{NH}_{3}\right)$. Inorg Chim Acta 203: $205-217$

Bottomley F (1978) Nitrosyl complexes of ruthenium. Coord Chem Rev 26: 7-32

Cheshire DR (2001) Use of nitric oxide synthase inhibitors for the treatment of inflammatory disease and pain. Drugs 4: 795-802

Clarke MJ (2002) Ruthenium metallopharmaceuticals. Coord Chem Rev 232: 69-93

Clarke MJ, Zhu F, Frasca DR (1999) Non-platinum chemotherapeutic metallopharmaceuticals. Chem Rev 99: 2511-2533

Cobb JP (1999) Use of nitric oxide synthase inhibitors to treat septic shock: the light has changed from yellow to red. Crit Care Med 27: 855-856

Cobbs CS, Brenman JE, Alpade KD, Bredt DS, Israel MA (1995) Expression of nitric oxide synthase in human central nervous system tumors. Cancer Res 55: 727-730

Davies NA, Wilson MT, Slade E, Fricker SP, Murrer BA, Powell NA, Henderson GR (1997) Kinetics of nitric oxide scavenging by rutheniu$\mathrm{m}(\mathrm{III})$ polyaminocarboxylates: novel therapeutic agents for septic shock. Chem Commun 47-48

Diamantis AA, Dubrawsky JV (1981) Preparation and structure of ethylenediaminetetraacetate complexes of ruthenium(II) with dinitrogen, carbon monoxide, and other $\pi$-acceptor ligands. Inorg Chem 20: 1142 1150

Feng C, Wang L, Jiao L, Liu B, Zheng S, Xie X (2002) Expression of p53, inducible nitric oxide synthase and vascular endothelial growth factor in gastric precancerous and cancerous lesions: correlation with clinical features. BMC Cancer 2: 8

Fricker SP (1999) Nitrogen monoxide-related disease and nitrogen monoxide scavengers as potential drugs. Met Ions Biol Syst 36: $665-721$

Fricker SP, Slade E, Powell NA, Vaughan OJ, Henderson GR, Murrer BA, Megson IL, Bisland SK, Flitney FW (1997) Ruthenium complexes as nitric oxide scavengers: a potential therapeutic approach to nitric oxidemediated diseases. Br J Pharmacol 122: 1441 - 1449

Fukumura D, Yuan F, Endo M, Jain RK (1997) Role of nitric oxide in tumor microcirculation. Blood flow, vascular permeability, and leukocyteendothelial interactions. Am J Pathol 150: 713-725

Furchgott RF, Zawadzki JV (1980) The obligatory role of endothelial cells in the relaxation of arterial smooth muscle by acetylcholine. Nature 288: 373-376

Gallo O, Masini E, Morbidelli L, Franchi A, Fini-Storchi I, Vergari WA, Ziche M (1998) Role of nitric oxide in angiogenesis and tumor progression in head and neck cancer. J Natl Cancer Inst 90: 587-596

Garvey EP, Oplinger JA, Furfine ES, Kiff RJ, Laszlo F, Whittle BJ, Knowles RG (1997) 1400W is a slow, tight binding, and highly selective inhibitor of inducible nitric-oxide synthase in vitro and in vivo. J Biol Chem 272: $4959-4963$

Jadeski LC, Hum KO, Chakraborty C, Lala PK (2000) Nitric oxide promotes murine mammary tumour growth and metastasis by stimulating tumour cell migration, invasiveness and angiogenesis. Int J Cancer 86: 30-39

Jadeski LC, Lala PK (1999) Nitric oxide synthase inhibition by $N(\mathrm{G})$-nitroL-arginine methyl ester inhibits tumor-induced angiogenesis in mammary tumors. Am J Pathol 155: $1381-1390$

Klotz T, Bloch W, Volberg C, Engelmann U, Addicks K (1998) Selective expression of inducible nitric oxide synthase in human prostatic carcinoma. Cancer 82: 1897-1903

Kratz F, Hartmann M, Keppler B, Messori L (1994) The binding properties of two antitumor ruthenium(III) complexes to apotransferrin. J Biol Chem 269: $2581-2588$

Kung A, Pieper T, Wissiack R, Rosenberg E, Keppler BK (2001) Hydrolysis of the tumor-inhibiting ruthenium(III) complexes HIm trans[RuCl4(im) $\left.)_{2}\right]$ and $\mathrm{HInd}$ trans- $\left[\mathrm{RuCl}_{4}(\mathrm{ind})_{2}\right]$ investigated by means of HPCE and HPLC-MS. J Biol Inorg Chem 6: 292-299

Malina J, Novakova O, Keppler BK, Alessio E, Brabec V (2001) Biophysical analysis of natural, double-helical DNA modified by anticancer heterocyclic complexes of ruthenium(III) in cell-free media. J Biol Inorg Chem 6: 435-445

Matsubara T, Creutz C (1979) Properties and reactivities of pentadentate ethylenediaminetetraacetate complexes of ruthenium(III) and -(II). Inorg Chem 18: 1956- 1966

Mestroni G, Alessio E, Sava G, Pacor S, Coluccia M, Boccarelli A (1994) Water-soluble ruthenium(III)-dimethyl sulfoxide complexes: chemical behaviour and pharmaceutical properties. Metal Based Drugs 1: 41-63

Morbidelli L, Chang C-H, Douglas JG, Granger HJ, Ledda F, Ziche M (1996) Nitric oxide mediates mitogenic effect of VEGF on coronary venular endothelium. Am J Physiol 270: $\mathrm{H} 411$ - H415

Morbidelli L, Donnini S, Mitola S, Ziche M (2001) Nitric oxide modulates the angiogenic phenotype of middle-T transformed endothelial cells. Int Biochem Cell Biol 33: 305-313

Mosi R, Seguin B, Cameron B, Amankwa L, Darkes MC, Fricker SP (2002) Mechanistic studies on AMD6221: a ruthenium-based nitric oxide scavenger. Biochem Biophys Res Commun 292: 519-529

Orucevic A, Bechberger J, Green AM, Shapiro RA, Billiar TR, Lala PK (1999) Nitric-oxide production by murine mammary adenocarcinoma cells promotes tumor-cell invasiveness. Int J Cancer 81: 889-896

Parenti A, Morbidelli L, Cui XL, Douglas JG, Hood J, Granger HJ, Ledda F, Ziche M (1998) Nitric oxide is an upstream signal for vascular endothelial growth factor-induced extracellular signal-regulated kinases1-2 activation in postcapillary endothelium. J Biol Chem 273: $4220-4226$

Parenti A, Morbidelli L, Ledda F, Granger HJ, Ziche M (2001) The bradykinin/B1 receptor promotes angiogenesis by upregulation of endogenous FGF-2 in endothelium via the nitric oxide synthase pathway. FASEB J 15: 1487 - 1489

Pintus G, Tadolini B, Posadini AM, Sanna B, Debidda M, Bennardini F, Sava G, Ventura C (2002) Inhibition of the MEK/ERK signaling pathway by a novel antimetastatic agent NAMI-A down regulates $c$-myc gene expression and endothelial cell proliferation. Eur J Biochem 269: 5861 5870

Sanna B, Debidda M, Pintus G, Tadolini B, Posadino AM, Bennardini F, Sava G, Ventura C (2002) The anti-metastatic agent imidazolium transimidazoledimethylsulfoxide-tetrachlororuthenate induces endothelial cell apoptosis by inhibiting the mitogen-activated protein kinase/ extracellular signal-regulated kinase signaling pathway. Arch Biochem Biophys 403: 209-218

Sava G, Bergamo A (1999) Drug control of solid tumour metastases: a critical view. Anticancer Res 19: $1117-1124$

Swaroop GR, Kelly PA, Bell HS, Shinoda J, Yamaguchi S, Whittle IR (2000) The effects of chronic nitric oxide synthase suppression on glioma pathophysiology. Br J Neurosurg 14: 543-548

Thomsen LL, Lawton FG, Knowles RG, Beesley JE, Riveros-Moreno V, Moncada S (1994) Nitric oxide synthase activity in human gynaecological cancer. Cancer Res 54: $1352-1354$

Thomsen LL, Scott JMJ, Topley P, Knowles RG, Keerie AJ, Frend AJ (1997) Selective inhibition of inducible nitric oxide synthase inhibits tumor growth in vivo. Studies with $1400 \mathrm{~W}$, a novel inhibitor. Cancer Res 57: $3300-3304$

Vacca A, Bruno M, Boccarelli A, Coluccia M, Ribatti D, Bergamo A, Garbisa S, Sartor L, Sava G (2002) Inhibition of endothelial cell functions and of angiogenesis by the metastasis inhibitor NAMI-A. Br J Cancer 86: 993- 998

Wink DA, Vodovotz Y, Laval J, Laval F, Dewhirst MW, Mitchell JB (1998) The multifaceted roles of nitric oxide in cancer. Cancerogenesis 19: 711-721 
Nitric oxide scavengers and angiogenesis

L Morbidelli et al

Ziche M, Morbidelli L (2000) Nitric oxide and angiogenesis. J Neurooncol 50: $139-148$

Ziche M, Morbidelli L, Choudhuri R, Zhang HT, Donnini S, Granger HJ, Bicknell R (1997) Nitric oxide synthase lies downstream from vascular endothelial growth factor-induced but not basic fibroblast growth factorinduced angiogenesis. J Clin Invest 99: 2625-2634

Ziche M, Morbidelli L, Masini B, Amerini S, Granger HJ, Maggi CA, Geppetti P, Ledda F (1994) Nitric oxide mediates angiogenesis in vivo and endothelial cell growth and migration in vitro promoted by substance P. J Clin Invest 94: 2036-2044

Zorzet S, Bergamo A, Cocchietto M, Sorc A, Gava B, Alessio E, Iengo E, Sava G (2000) Lack of in vitro cytotoxicity, associated to increased G(2)-M cell fraction and inhibition of matrigel invasion, may predict in vivoselective antimetastasis activity of ruthenium complexes. J Pharmacol Exp Ther 295: $927-933$ 